This PDF is a selection from an out-of-print volume from the National Bureau of Economic Research

Volume Title: Evaluation of Econometric Models

Volume Author/Editor: Jan Kmenta and James B. Ramsey, eds.

Volume Publisher: Academic Press

Volume ISBN: 978-0-12-416550-2

Volume URL: http://www.nber.org/books/kmen80-1

Publication Date: 1980

Chapter Title: Some Comments on the Role of Time-Series Analysis in Econometrics

Chapter Author: C. W. J. Granger

Chapter URL: http://www.nber.org/chapters/c11709

Chapter pages in book: (p. 339 - 341) 


\title{
Some Comments on the Role of Time-Series Analysis in Econometrics
}

\author{
C.W.J. GRANGER \\ DEPARTMENT OF ECONOMICS \\ UNIVERSITY OF CALIFORNIA, SAN DIEGO \\ LA JOLLA, CALIFORNIA
}

For most of the past 20 years, time-series analysts and classical econometricians have treated each other as antagonists. The econometricians would recognise the output of the time-series analysts as sources for what they called "naïve" forecasts to be used in contests against forecasts based on their own models. They were frequently embarrassed when the naïve forecasts proved superior. More recent contests have provided closer races, partly because the two approaches have moved together, as the papers in this session very well illustrate. Ten years ago a conference such as this would not have included a time-series section, but now many of the papers in all sessions include time-series concepts as standard procedures. A further development has been the virtual disappearance of the division within the time-series analysts, where for a period one was either a frequencydomain analyst or a time-domain type. Now, it is common to switch from one domain to another and back again. These developments are, of course, extremely healthy, and everyone concerned can only benefit. In my opinion, the econometricians have benefited the most over the past five years, but the opposite will be true in the next five years, when the time-series analysts turn their attention more to the question of how to model multiple series. Both groups of research workers have the same eventual aim, the production of sound models of the economy, and it should not be long before their methods become virtually indistinguishable.

Howrey has provided us with a comprehensive nice survey of how timeseries methods have affected econometrics. The only major topic that I think is missing is the contribution of optimum forecast theory to the 
rational expectations literature. In my opinion, the most important impact of time-series methods has been to force econometricians to think more carefully about the time-series properties of the residuals of their equations. The time-series analysts have always been more careful, as the papers by Howrey and Engle show. An econometrician can no longer just assume that his residuals are white noise or, if slightly more sophisticated, first-order autoregressive (AR(1)). It is easy to show that $A R(1)$ is an unlikely model to be correct for residuals and, in my experience, it rarely occurs in practice. Better assumptions about the time-series model for residuals necessitate more difficult estimation procedures but should lead to more efficient parameter estimates, reduce the likelihood of spurious relationships and also improve forecasts.

The time-series community has only recently turned to multiple series modeling problems. Howrey illustrates how one-way causal models may be identified and estimated. In a recent book by Paul Newbold and myself (Granger \& Newbold, 1977), we suggest a method whereby feedback, or two-way causal, models may potentially be identified. However, progress along these lines is rather difficult, particularly with series of the length and instability found in economics. One use of such models involves time-series analysis of residuals, henceforth TSAR, the residuals being those from econometric models. This should represent a fairly uncontroversial amalgamation of the time-series and econometric approaches. An econometrician after building a model using any economic theory or other prior information he feels is important, should have nothing to say about his residuals except that they should be white noise and be uncorrelated overtime, though possibly correlated contemporaneously. TSAR will provide a test if this is so. Single-series methods applied to individual equation residuals will determine if they can be forecast from their own past. Bivariate modeling of residuals from pairs of equations will help to determine if the model is correctly specified. In this way missing exogenous, endogenous, and lagged dependent variables can, in principle, be detected and possible improvements can be suggested. TSAR has been applied to the St. Louis model (Ashley \& Granger, 1979) and is currently being applied to Ray Fair's (1976) model. In both cases some potentially useful respecification of the model has been suggested by the analysis.

I do not feel that I am the best person to discuss the Wallace-Hatanaka paper, as I am not in favour of the use of constrained distributed lag models. I do not understand why, except for a few very exceptional data sets, one should assume the existence of a one-sided causal situation with severely limiting constraints, such as a lag structure constrained to lie on a particular smooth curve, positive coefficients, or white noise residuals. Having said that, if the distributed lag approach is thought appropriate in some situation, the authors appear to have provided some useful and ingenious results 
concerning the likely properties of the distribution of the lag coefficients. To someone unversed in distributed lag procedures the obvious question to ask is Why is the $X_{t}$ series not filtered to give either white noise or a highly autocorrelated series, whichever is required, before building the model? Presumably the answer lies in some strong underlying economic theory that is being applied and that greatly determines the form of the model.

It is difficult to comment on the work of a close colleague, but Engle's approach does seem to be both very general and computationally convenient. A number of further generalizations and applications seem possible and are obviously worth considering. One possibility is to use this approach to the question of testing for causality, a problem that at this time is in a state of considerable flux.

\section{REFERENCES}

Ashley, R., \& Granger, C. W. J. Time series analysis of residuals from the St. Louis model. Journal of Macroeconomics, 1979, 1, 373-394.

Fair, R. C. A model of macroeconomic activity. Cambridge, Mass.: Ballinger Publishing Co., 1976. 2 vols.

Granger, C. W. J., \& Newbold, Paul. Forecasting economic time series. New York: Academic Press, 1977. 